\title{
Involvement of informal caregivers in supporting patients with COPD: a review of intervention studies
}

Jamie Bryant ${ }^{1,2}$

Elise Mansfield ${ }^{1,2}$

Allison W Boyes ${ }^{1,2}$

Amy Waller ${ }^{1,2}$

Rob Sanson-Fisher ${ }^{1,2}$

Timothy Regan ${ }^{1,2}$

'Health Behaviour Research Group, Priority Research Centre for Health Behaviour, ${ }^{2}$ Hunter Medical Research Institute, University of Newcastle, Callaghan, NSW, Australia
Correspondence: Jamie Bryant Health Behaviour Research Group, University of Newcastle, Lot I Kookaburra Circuit, New Lambton Heights, NSW 2305, Australia

Tel +6I 240420709

Fax +6I 240420040

Email jamie.bryant@newcastle.edu.au
This article was published in the following Dove Press journal:

International Journal of COPD

14 July 2016

Number of times this article has been viewed
Abstract: Caregivers of individuals with COPD have a key role in maintaining patient adherence and optimizing patient function. However, no systematic review has examined how the caregiver role has been operationalized in interventions to improve outcomes of individuals with COPD or the quality or effectiveness of these interventions. The aims of this review were to 1) determine whether caregivers have been involved as part of interventions to improve outcomes of individuals with COPD; 2) determine the risk of bias within included intervention studies; and 3) examine the effectiveness of interventions that have involved caregivers in improving outcomes of individuals with COPD. The electronic databases of Medline, Embase, PsycINFO, and Cochrane Library were searched from January 2000 to November 2015. Experimental studies testing interventions that involved a caregiver to improve COPD patient outcomes were eligible. Nine studies involving caregivers met inclusion criteria. No studies reported any intervention components targeted solely at caregivers, with most instead including caregivers in dyadic or group education sessions about COPD delivered by health care professionals. The risk of bias identified in included studies was mixed. Seven of the nine studies were effective in improving a broad range of outcomes. These findings highlight that there is an urgent need for methodologically rigorous interventions to examine the effectiveness of strategies to assist caregivers to provide direct care, encourage adherence to health care provider recommendations, act as a health care advocate, and provide emotional and psychosocial support to individuals with COPD.

Keywords: COPD, carer, support persons, intervention studies

\section{Introduction}

COPD is a progressive chronic disease characterized by debilitating symptoms that include difficult breathing, cough, and limitations in airflow to the lungs. ${ }^{1}$ COPD has major negative impacts on the physical, psychological, and social well-being of those living with the disease and their caregivers. ${ }^{2}$ Globally, COPD is estimated to affect $>9.7 \%$ of people aged $>40$ years $^{3}$ and is projected to be the third leading cause of death in $2030 .^{4}$

Although COPD is treatable, it is not completely reversible. ${ }^{5}$ Strict adherence to clinical practice guidelines is therefore recommended for patients to experience optimal relief from ongoing symptoms. ${ }^{6}$ International COPD guidelines recommend multiple strategies to maximize function, reduce the severity and frequency of exacerbations, and limit the overall progression of disease. ${ }^{7}$ These strategies include (but are not limited to) cessation of tobacco use, appropriate pharmacologic therapy, participation in pulmonary rehabilitation, and engagement in physical activity. Adherence to these 
recommendations has been shown to improve quality of life, slow progression of disease, and reduce exacerbations and hospitalizations. ${ }^{2,8}$ For example, smoking cessation has been linked to slow the decline in lung functioning, ${ }^{9}$ and pulmonary rehabilitation is associated with increased capacity for exercise ${ }^{10}$ and quality of life. ${ }^{11}$ Despite this, the rate of COPD treatment adherence among developed countries is estimated to be as low as $50 \%{ }^{12}$ An Australian study of individuals with COPD found that $24 \%$ were current smokers and $51 \%$ did not adhere to prescribed medications. ${ }^{13}$ Smoking cessation success rate (ie, abstinence sustained for 5 years) among patients with COPD in the US and Canada was just $22 \%$. Medication adherence rates in clinical trials may be as high as $70 \%-90 \%$, yet in clinical practice the rates range from $10 \%$ to $40 \%{ }^{2}$

The reasons for poor adherence are multifactorial and complex. These may include limited patients' understanding of their disease, polytherapy, inaccurate views about the potential benefits, and/or risks of treatment, depression, poor patient-provider communication, and a lack of family or social support., ${ }^{2,14}$ Poor adherence among individuals with COPD suggests the need for ongoing monitoring and support to effect behavior change and maintain adherence. ${ }^{15}$ Similar to other chronic disease contexts, ${ }^{16,17}$ informal caregivers of patients with COPD represent potential agents of change that can facilitate and enhance adherence to COPD management behaviors. ${ }^{18}$

According to social learning theory, ${ }^{19}$ cognition, environment, and behavior interact. Therefore, an individual's social environment is particularly important in shaping their cognitions and behavior. Informal caregivers are individuals who have a personal relationship with the person with $\mathrm{COPD}^{20}$ and often provide unpaid help or supervision with tasks such as assistance and support in monitoring disease progression, assisting with adherence to recommended treatments, encouraging and facilitating appropriate medical treatment when needed, and supporting optimal psychosocial well-being. ${ }^{21}$ Consistent evidence across a number of disease types indicates that caregiver support influences patient adherence and health outcomes. ${ }^{22-24}$ For example, a cross-sectional study found that individuals with COPD who had caregiver support had higher rates of adherence to antihypertensive and long-acting beta agonist medications than those without and were also less likely to smoke. ${ }^{23}$ Despite the potential of informal caregivers in optimizing outcomes and supporting adherence to health care provider recommendations, there is a lack of understanding about how caregivers have been involved in strategies to improve outcomes of individuals with COPD.

\section{Aims}

This systematic review aimed to

1. Determine whether caregivers have been involved as part of interventions to improve outcomes of individuals with COPD;

2. Determine the risk of bias of intervention studies that have involved caregivers in improving outcomes of individuals with COPD;

3. Examine the effectiveness of interventions that have involved caregivers in improving outcomes of individuals with COPD.

\section{Methods \\ Definitions}

Caregivers are defined as "any person who, without being a professional or belonging to a social support network, usually lives with the patient and, in some way, is directly implicated in the patient's care or is directly affected by the patient's health problem". ${ }^{25}$

\section{Literature search}

The electronic databases Medline, Embase, PsycINFO, and Cochrane Library were searched using Medical Subject Headings (MeSH) and keywords (Supplementary materials). The main themes included in the search terms were "caregivers" and "COPD", which were combined using the Boolean operator AND. Searches were limited to English language studies published on human subjects between January 2000 and November 2015. Only articles published from 2000 onward were included to coincide with the release of the Institute of Medicine's “Crossing the Quality Chasm" report, given its emphasis on the important role of caregivers in achieving patient-centered care. ${ }^{26}$ The reference lists of all relevant identified studies were also manually searched to identify additional studies that met inclusion criteria.

\section{Inclusion and exclusion criteria}

Eligible studies were those that used an experimental design to test the effectiveness of an intervention that included some role for a caregiver in order to improve the outcomes of the individual with COPD. Studies were included only if they used one of the acceptable Effective Practice and Organisation of $\mathrm{Care}^{14}$ (EPOC) designs (ie, randomized controlled trial, nonrandomized controlled trial, controlled before and after study, or interrupted time series trial). Only quantitative studies were included as other recent reviews provide an analysis of qualitative evidence about the experiences of caregivers of COPD..$^{27,28}$ Studies that included caregivers of individuals with other chronic illnesses were only included 
if outcomes were reported separately for caregivers of individuals with COPD. Publications that focused on caregiver burden or the unmet needs of caregivers were excluded. Case studies, commentaries, reviews, conference abstracts, protocol articles, editorials, and studies not published in English were also excluded.

\section{Data coding}

All retrieved abstracts were initially assessed by one author (JB or EM) against the inclusion and exclusion criteria and rejected if the study did not meet eligibility criteria based on assessment of the title and abstract. The remaining full-text articles were then independently reviewed by two authors (EM and JB), and studies that met all criteria were retained for review. Discrepancies between reviewers were discussed until an agreement was reached on article inclusion or exclusion. Where agreement could not be reached, a third author was consulted. The risk of bias of included studies was assessed against the nine EPOC "Risk of Bias" criteria by two reviewers (JB and EM). Discrepancies between reviewers' coding of risk of bias were discussed until an agreement was reached.

\section{Data extraction}

The following information was extracted from included studies to determine the role of caregivers in the intervention and assess intervention effectiveness: sample characteristics (number of participants, age, sex, and diagnosis), inclusion and exclusion criteria, details of the intervention and control conditions, outcome measures, follow-up time points, findings, and specified caregiver role (Tables 1 and 2).

\section{Data synthesis}

Meta-analysis of study findings was not possible due to heterogeneity in study outcomes. A narrative analysis was therefore conducted. The effectiveness of included intervention studies is reported by the type of intervention used (hospital at home interventions, discharge coordinator interventions, and self-management interventions).

\section{Results}

\section{Search results}

A total of 1,741 citations were retrieved, in which 232 fulltext manuscripts were assessed against eligibility criteria, with nine intervention studies meeting criteria for inclusion in the review. A summary of the selection process following the Preferred Reporting Items for Systematic Reviews and Meta-Analysis (PRISMA) ${ }^{29}$ four-phase flow diagram is provided in Figure 1.

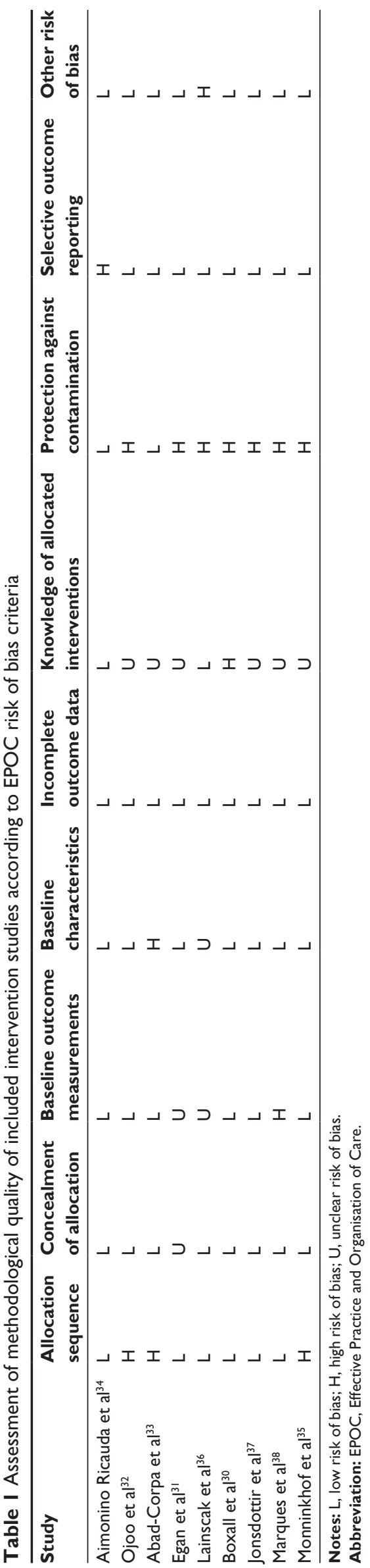


Table 2 Summary of the roles caregivers can adopt in supporting patients

\begin{tabular}{|c|c|c|}
\hline Role & Description & Benefit of caregiver involvement \\
\hline Informational & $\begin{array}{l}\text { Learning about the disease, its progression, prognosis, } \\
\text { and treatment options }\end{array}$ & $\begin{array}{l}\text { Allows caregiver to clarify and reinforce information } \\
\text { to the patient } \\
\text { Assists with reducing uncertainty and increasing } \\
\text { confidence in decision making }{ }^{40}\end{array}$ \\
\hline Providing direct care & $\begin{array}{l}\text { Providing assistance with medications, symptom } \\
\text { management, and activities of daily living }\end{array}$ & \\
\hline Encouraging adherence & $\begin{array}{l}\text { Supporting and encouraging patients to adhere to } \\
\text { treatment regimens or self-management programs }\end{array}$ & $\begin{array}{l}\text { Caregiver support has been shown to increase } \\
\text { treatment adherence and self-care behaviors }{ }^{41,42} \\
\text { May enhance patient skills and confidence to engage } \\
\text { in self-care }\end{array}$ \\
\hline Acting as an advocate & $\begin{array}{l}\text { Assisting to coordinate care across providers and settings } \\
\text { Liaising with organizations and health care providers to } \\
\text { secure patient entitlements, services, and care }\end{array}$ & $\begin{array}{l}\text { Can enhance communication with the health care team } \\
\text { An increased understanding of and control over their } \\
\text { treatment options, and higher quality of life }{ }^{43,44}\end{array}$ \\
\hline $\begin{array}{l}\text { Providing emotional or } \\
\text { psychosocial support }\end{array}$ & $\begin{array}{l}\text { Providing empathy and validation of the patient } \\
\text { experience, encouraging patient self-efficacy, coordinating } \\
\text { family responsibilities, or taking on new family roles }\end{array}$ & $\begin{array}{l}\text { Can reduce patient distress }{ }^{45} \\
\text { Can lead to improved communication between the } \\
\text { patient and caregiver }{ }^{46}\end{array}$ \\
\hline
\end{tabular}

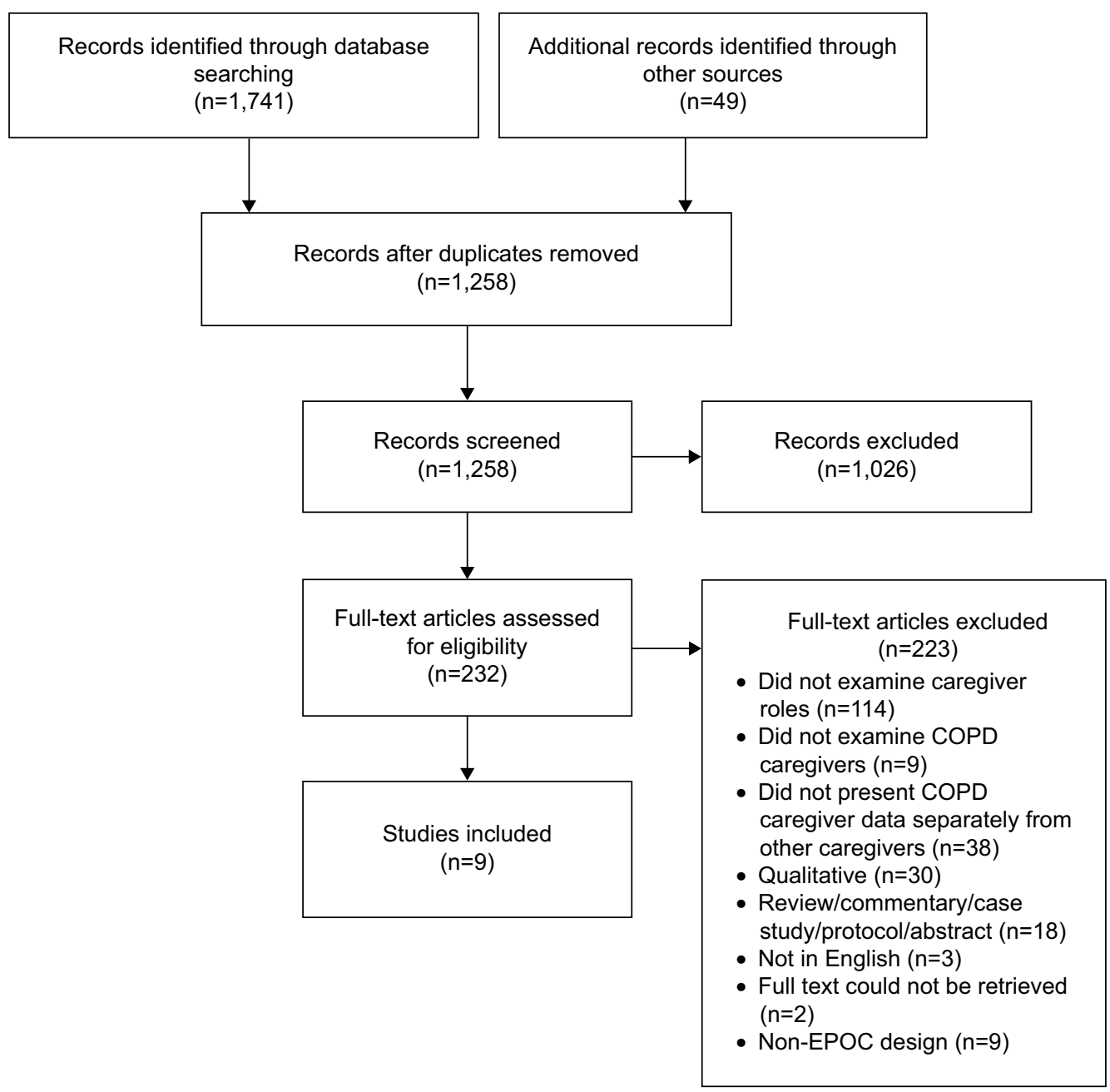

Figure I PRISMA flow chart of search results.

Abbreviations: EPOC, Effective Practice and Organisation of Care; PRISMA, Preferred Reporting Items for Systematic Reviews and Meta-Analysis. 


\section{Characteristics of included studies}

The characteristics of included studies are provided in the Supplementary materials. Two studies were conducted in Australia, ${ }^{30,31}$ whereas one study each was conducted in the UK, ${ }^{32}$ Spain, ${ }^{33}$ Italy, ${ }^{34}$ the Netherlands, ${ }^{35}$ Slovenia, ${ }^{36}$ Iceland, ${ }^{37}$ and Portugal. ${ }^{38}$ Two studies reported on hospital at home interventions, ${ }^{32,34}$ three studies described a discharge coordinator intervention, ${ }^{31,33,36}$ and four studies reported on self-management interventions..$^{30,35,37,38}$ The outcomes assessed were diverse, but commonly included hospital admission or readmission, ${ }^{30-34,36}$ health-related quality of life using the St George Respiratory Questionnaire, ${ }^{30,31,33,35-38}$ and functional capacity using the 6-minute walk test. . $^{30,35,38}$ Length of follow-up varied across studies, ranging from a single follow-up at 2 weeks ${ }^{32}$ to multiple follow-up assessments up to 1 year..$^{35}$

\section{Risk of bias}

The risk of bias of included studies is provided in Table 1 . Five studies were randomized controlled trials, ${ }^{30,31,34,36,38}$ and four were controlled clinical trials. . $2,33,35,37$ The risk of bias of intervention studies was mixed. Three studies were rated as low risk on seven or more of the nine EPOC criteria. ${ }^{30,34,37}$ The remaining studies were rated as low risk on five $\mathrm{e}^{31,36}$ or $\operatorname{six}^{32,33,35,38}$ of the criteria and suffered from a range of limitations. Three studies were rated as high risk of bias due to the allocation sequence used,,$^{32,33,35}$ whereas one study ${ }^{31}$ did not adequately report a method of allocation concealment. Two studies did not report whether outcome measures were similar at baseline, ${ }^{31,36}$ and in one study there were significant differences in the baseline characteristics of participants. ${ }^{33}$ Five studies did not specify whether knowledge of group allocation was prevented during assessment, ${ }^{30-33,35,37}$ and in one study, knowledge of allocation was not prevented. ${ }^{30}$ In most studies, there was a high risk of patients in the control group also receiving the intervention, leading to potential contamination. ${ }^{30-32,35-38}$

\section{Roles of caregivers}

Table 3 outlines the roles of caregivers in each of the included interventions. In all studies, interventions were targeted at the patient and caregiver dyad; no studies included intervention components designed uniquely to support the caregiver. In all of the identified studies, caregivers were included with the patient in individual or group education sessions about COPD provided by health care professionals. Other intervention strategies included asking the dyad about problems they thought might arise when the patient was discharged home, ${ }^{33}$ telephone calls from a care manager to the dyad to monitor outcomes, ${ }^{31}$ discussions with a clinical nurse specialist to discuss concerns, ${ }^{37}$ and involvement in the discharge planning process. ${ }^{36}$

Table 3 Specified roles of caregivers in each intervention

\begin{tabular}{|c|c|c|c|}
\hline \multirow[t]{2}{*}{ Study } & \multirow[t]{2}{*}{ Specified caregiver role } & \multicolumn{2}{|c|}{ Provided to } \\
\hline & & $\begin{array}{l}\text { Caregiver } \\
\text { only }\end{array}$ & $\begin{array}{l}\text { Patient-caregiver } \\
\text { dyad }\end{array}$ \\
\hline Aimonino Ricauda et $\mathrm{al}^{34}$ & Provided with education about COPD & & $\mathrm{X}$ \\
\hline Ojoo et $\mathrm{al}^{32}$ & $\begin{array}{l}\text { Provided with education about COPD and provided with "reassurance" } \\
\text { (no further details provided) }\end{array}$ & & $X$ \\
\hline \multirow[t]{2}{*}{ Abad-Corpa et al ${ }^{33}$} & Provided with education about COPD & & $X$ \\
\hline & $\begin{array}{l}\text { Asked for information about problems or needs that might arise on arrival } \\
\text { at home }\end{array}$ & & $X$ \\
\hline \multirow[t]{2}{*}{ Egan et $\mathrm{al}^{31}$} & Provided with education about COPD & & $\mathrm{X}$ \\
\hline & $\begin{array}{l}\text { Received phone calls on a regular basis from the care manager to ensure that } \\
\text { planned outcomes were achieved }\end{array}$ & & $\mathrm{X}$ \\
\hline \multirow[t]{2}{*}{ Lainscak et $\mathrm{al}^{36}$} & Provided with education about COPD & & $\mathrm{X}$ \\
\hline & $\begin{array}{l}\text { Actively involved in discharge planning process (which involved discharge } \\
\text { coordinator assessing patient situation and homecare needs) }\end{array}$ & & $\mathrm{X}$ \\
\hline Boxall et $\mathrm{al}^{30}$ & Provided with education about COPD & & $\mathrm{X}$ \\
\hline \multirow[t]{2}{*}{ Jonsdottir et $\mathrm{al}^{37}$} & $\begin{array}{l}\text { Provided with education about COPD including skills in communication with } \\
\text { family, relatives, and health professionals }\end{array}$ & & $X$ \\
\hline & $\begin{array}{l}\text { Included in 3-4 semistructured conversations with a clinical nurse specialist in } \\
\text { respiratory nursing to discuss main concerns, symptoms, nature of the disease, } \\
\text { and possibilities for patient/family to prevent further decline of disease within } \\
\text { the aim of enhancing health of the patient and family }\end{array}$ & & $\mathrm{X}$ \\
\hline Marques et $\mathrm{al}^{38}$ & Invited to attend weekly psychosocial support and education sessions & & $\mathrm{X}$ \\
\hline Monninkhof et $\mathrm{al}^{35}$ & Invited to attend group education sessions about COPD & & $\mathrm{X}$ \\
\hline
\end{tabular}




\section{Intervention effectiveness}

\section{Hospital at home interventions}

Two studies examined the effectiveness of a hospital at home intervention compared to usual inpatient hospital care, showing conflicting results. Aimonino Ricauda et $\mathrm{a} \mathrm{l}^{34}$ compared a geriatric home hospitalization service of physician and nurse visits and education and geriatric assessments with routine hospital care for patients with acute exacerbation of COPD requiring hospitalization. At 6-month follow-up, patients in the intervention group had lower rates of hospital readmissions and greater improvements in depression and quality of life compared with the control group. However, a study by Ojoo et $\mathrm{al}^{32}$ that also examined the effectiveness of a hospital at home intervention for individuals with an acute exacerbation of COPD admitted to hospital did not find any improvements in patient outcomes. Patients were sent home within 48 hours of admission with a discharge package that included bronchodilators, steroids, antibiotics, and oxygen as required, and respiratory outreach nurses monitored patients daily and provided patient and caregiver education and reassurance. No differences were found between the intervention and control groups in symptoms, readmission rate, and mortality at follow-up.

\section{Discharge coordinator interventions}

Three studies described the effectiveness of discharge coordinator interventions. Each of these interventions resulted in significant improvements in patient outcomes, which included quality of life, social support, and hospital readmissions. Abad-Corpa et al ${ }^{13}$ reported on the effectiveness of an intervention for patients admitted to hospital with a primary diagnosis of COPD that included five daily visits by nurses during the patient's hospital admission and one visit after discharge. Visits involved: educating the patient and caregiver about the disease; identifying any problems or needs arising during hospitalization or any anticipated needs on arrival at home; and putting the patient, caregiver, and the health care team in contact with other professionals as needed. The intervention group showed significantly greater improvements in quality of life and knowledge of therapeutic regime compared with the control group. Lainscak et $\mathrm{al}^{36}$ examined the effectiveness of telephone support from a discharge coordinator who provided information and actively involved the patient and caregiver in the discharge planning process for patients admitted to hospital with acute exacerbation of COPD. Patients were contacted by phone 48 hours after discharge, with additional calls made as requested. At 180-day follow-up, there were significantly fewer hospitalizations for the intervention group compared with the control group. Egan et al ${ }^{31}$ reported on the effectiveness of discharge intervention led by a case manager for patients admitted to hospital with COPD and a history of chronic bronchitis (with infection), emphysema, chronic airway obstruction, chronic asthma, or a combination of these. During hospitalization, the case manager carried out a comprehensive nursing assessment to identify any needs, facilitated communication between the patient, caregiver, and health care professionals, provided education to the patient and caregiver on managing medications and rehabilitation, and facilitated discharge planning. Following discharge, the case manager provided ongoing support and acted as a referral point for community services. Although there were no significant differences between the intervention and control groups in unscheduled hospital readmissions, the intervention group reported increased affectionate support, and increased activity from 1-month to 3-month follow-up.

\section{Self-management interventions}

Four studies reported on interventions that aimed to enhance patient self-management. The effectiveness of these interventions was mixed. Monninkhof et $\mathrm{al}^{35}$ examined the effectiveness of a self-management education course for patients and caregivers. Patients were eligible if they had a clinical diagnosis of stable COPD, no history of asthma or exacerbation in the month prior to study enrollment, were aged 40-75 years, and a current or former smoker. The intervention covered insight into the nature of the disease, guidelines for self-treatment of exacerbations, relaxation, exercise, energy conservation, and changing role patterns, as well as a fitness program for patients. There were no significant differences between intervention and control groups in quality of life, well-being, self-confidence, or functional exercise capacity, and only a marginally significant reduction in two symptoms (cough and sputum color). Although caregivers were invited to attend educational sessions, their rates of attendance were not reported. Jonsdottir et $a l^{37}$ examined the effectiveness of a self-management intervention for individuals aged 45-65 years with mild or moderate COPD. The intervention included semistructured conversations with a clinical nurse specialist in respiratory nursing, the provision of smoking cessation treatment, and a group educational meeting. No significant differences were found between the intervention and control groups for depression, anxiety, total self-reported exercise, self-reported exacerbations in the previous 6 months, or smoking status. The rate of attrition among caregivers was high, with $31 \%$ in the experimental 
condition and $50 \%$ in the control condition dropping out by 12-month follow-up.

The remaining two self-management interventions incorporated pulmonary rehabilitation. Boxall et $\mathrm{al}^{30}$ examined the effectiveness of a 12-week home-based pulmonary rehabilitation intervention among patients with COPD aged $>60$ years, who were free from worsening symptoms of disease over the last 2 weeks. The home-based pulmonary rehabilitation intervention, which comprised walking and arm exercises, physiotherapy visits, education sessions for patients and caregivers, controlled breathing techniques, energy conservation, use of aids and stress management, showed a significantly greater improvement from baseline to 12-week follow-up in functional exercise capacity and quality of life, as well as a decrease in breathlessness. ${ }^{30}$ There was no difference in the rate of hospital admission or length of stay at 12 weeks; however, at 6 months the intervention group showed a significantly lower length of stay compared with the control group. Marques et $\mathrm{a}^{138}$ examined the effectiveness of a 12-week family based pulmonary rehabilitation program for individuals with COPD and their family members. The intervention comprised exercise training for individuals with COPD (three sessions per week of 1-hour duration each) as well as weekly psychosocial support and education sessions demonstrated improved coping compared with usual pulmonary rehabilitation. No differences in psychosocial adjustment, exercise tolerance, functional balance, knee extensors strength, and quality of life were found. ${ }^{38}$

\section{Discussion}

A diagnosis of COPD is associated with significant burden for both the individual diagnosed and their caregiver(s). Poor adherence to recommended treatment by individuals with COPD is consistently reported in the literature, resulting in increased rates of morbidity, health care utilization, cost, and reduced quality of life. Informal caregivers have a key role to play in aiding adherence and optimizing patient outcomes. This review describes the extent and manner in which intervention studies have involved caregivers in improving outcomes of individuals with COPD and the effectiveness of these interventions in improving outcomes for individuals with COPD.

\section{Scope of caregiver involvement in interventions is limited}

None of the studies identified in this review specifically aimed to increase caregivers' capacity to support the individual with COPD. All of the identified studies focused on delivering education about COPD to the patient and caregiver as a dyad. Only three studies incorporated additional intervention components that were directed at the patient and caregiver as a dyad; however, these were poorly described. Simply involving caregivers in interventions targeted at individuals with COPD is unlikely to adequately equip caregivers with the array of skills they need to effectively support individuals with COPD to optimally manage their condition.

\section{Risk of bias of identified studies is high}

Only nine intervention studies meeting the EPOC design criteria were identified that incorporated a role for caregivers, indicating a dearth of rigorous research in this area. The risk of bias of included studies was variable, with studies suffering from a range of limitations that reduce the strength of the evidence. The most poorly met criterion was protection against contamination. This may reflect the reliance on education as the intervention strategy. It is argued that trials of educational interventions may be prone to contamination as the active ingredients may be easily accessible by control participants. ${ }^{3}$ For example, there is a greater potential for contamination when education is delivered by a single health care provider who also provides care for control participants. This has the potential to dilute intervention effects and may contribute to the mixed findings between studies. Improved report on the nature and impact of contamination has been identified as a priority.

\section{Interventions are promising but more evidence is needed}

A major limitation of the current evidence base is the lack of trials testing the differential effectiveness of caregiver involvement on COPD patient outcomes. An ideal future study would be a three-arm randomized controlled trial that compared the effectiveness of an intervention targeted at the COPD patient only, an intervention that included caregiver support and standard care. This would provide high-level evidence of the benefit of incorporating caregiver support as a core component of care. Despite the absence of such trials, seven of the nine identified studies that included caregivers were effective in improving a broad range of outcomes, including hospital admissions, quality of life, knowledge of treatment regimes, and symptom severity. Most of the interventions were targeted at patients who had been admitted to hospital with an acute exacerbation of COPD. All three of the discharge coordinator interventions were shown to be effective in improving patient outcomes, whereas hospital at home and self-management interventions showed mixed effectiveness. All of the intervention strategies 
tested included multiple elements, and it is unknown which element(s) produced the improvements in patient outcomes. Nevertheless, these findings suggest that there is significant scope to examine the way in which supporting caregivers can improve patient outcomes, in particular, not only during the discharge planning progress but also at home when the patient requires further support to self-manage. ${ }^{39}$

\section{How can we better support caregivers in COPD interventions?}

Research into the experiences of caregivers of individuals with other chronic diseases indicates that caregivers perform a wide range of complex roles. ${ }^{5}$ These roles can include providing assistance to gather information about the disease, its progression, prognosis, and treatment options; providing direct care; encouraging and supporting adherence to treatment recommendations; acting as an advocate to ensure that bestpractice care and support services are provided; and providing emotional and psychosocial support. All of these roles have specific advantages in facilitating optimal patient outcomes (Table 2). Consequently, future interventions should incorporate tailored content and/or strategies to assist the caregiver in supporting the patient across all of these roles to produce optimal outcomes. ${ }^{5}$ The fact that all three interventions that examined the effectiveness of improved discharge processes were effective in improving COPD patient outcomes suggests that further exploration of discharge coordinator interventions is warranted. These types of interventions are characterized by multiple sessions of either face-to-face or telephone support from a nurse with specific COPD expertise who provides ongoing support and/or acts as a referral point for community services for the patient and their caregiver. Such interventions could reasonably be broadened to include greater support to assist the caregiver in carrying out these roles. For example, the support provided as part of the discharge process could be strengthened by providing information about practical ways the caregiver can assist with medication adherence, empowering the caregiver to assist with coordinating care, and providing information to the caregiver about effective strategies for providing emotional or psychosocial support to the patient.

None of the interventions recruited patients and their caregivers at the time of diagnosis. Intervening too late in the illness trajectory may reduce the potential impact of any intervention on caregivers, as they may be too overwhelmed by their caregiving responsibilities to be receptive to learning new skills. Intervening earlier when the patient's symptoms are likely to be less severe has a greater potential for reaching caregivers. Intervening at this time also has the advantage of preparing caregivers for the roles they are likely to be required to perform. Such early interventions might include practical skill development, as well as anticipation of future events that might arise and providing practical strategies to manage these events. This preparedness may reduce burden and distress felt by both patients and their caregivers later in the illness trajectory.

\section{Future directions}

Given the aging population and growing burden of COPD, there is also an urgent need to ensure that interventions designed to support patients with COPD are cost-effective. Although this review found that interventions delivered face-to-face or by telephone have some evidence for improving outcomes in COPD populations, these approaches are burdensome in terms of the time and resources required by COPD patients, caregivers, and health care providers. Alternative modes of intervention delivery such as the use of digital technology should be considered. Although there is burgeoning interest in the use of cutting-edge technology to improve quality of care, surprisingly, none of the identified interventions used technology to support caregivers of patients with COPD. Technology can play an important role in both streamlining and standardizing data collection; can enhance the capacity for rapid information transfer between caregivers and health professionals; and can enable the flexible and tailored delivery of support to caregivers. For example, web-based interactive health communication applications are multidimensional tools that can provide ongoing support to caregivers in self-managing exacerbations. The use of such applications may represent a low-cost approach to developing caregiver skills, which may subsequently lead to reductions in health service use. To achieve these goals, interventions must be accessible to and be used as intended by caregivers. Strategies to maximize engagement and uptake must be considered in any intervention trials.

\section{Limitations}

Our findings should be considered in light of several limitations. First, only databases that included peer-reviewed publications were searched. It is possible that additional intervention studies meeting inclusion criteria exist in the unpublished gray literature. Second, although we aimed to describe how intervention studies involved caregivers in improving outcomes of individuals with COPD, the nature of this involvement was poorly described in studies. This therefore limits our ability to provide specific description of the role of caregivers. 


\section{Conclusion}

There is an urgent need for methodologically rigorous interventions to examine the effectiveness of strategies that directly assist caregivers to provide direct care, encourage adherence to health care provider recommendations, act as a health care advocate, and provide emotional and psychosocial support.

\section{Acknowledgments}

This manuscript was supported by a Strategic Research Partnership Grant from Cancer Council NSW to the Newcastle Cancer Control Collaborative. Infrastructure support was provided by the Hunter Medical Research Institute.

\section{Disclosure}

Doctor Jamie Bryant was supported by an Australian Research Council Postdoctoral Industry Fellowship. Doctor Allison Boyes was supported by a National Health and Medical Research Council Early Career Fellowship (APP1073317). Doctor Amy Waller was supported by an Australian Research Council Discovery Early Career Research Award (DECRA, DE150101262). The authors report no other conflicts of interest in this work.

\section{References}

1. Centers for Disease Control and Prevention (CDC). Chronic obstructive pulmonary disease among adults - United States, 2011. MMWR Morb Mortal Wkly Rep. 2012;61(46):938-943.

2. Seamark D, Blake SD, Seamark CJ, Halpin DM. Living with severe chronic obstructive pulmonary disease (COPD): perceptions of patients and their carers. An interpretative phenomenological analysis. Palliat Med. 2004;18(7):619-625.

3. Halbert R, Natoli JL, Gano A, Badamgarav E, Buist A, Mannino DM. Global burden of COPD: systematic review and meta-analysis. Eur Respir J. 2006;28(3):523-532.

4. Lopez AD, Shibuya K, Rao C, et al. Chronic obstructive pulmonary disease: current burden and future projections. Eur Respir J. 2006; 27(2):397-412.

5. Mannino DM, Buist AS. Global burden of COPD: risk factors, prevalence, and future trends. Lancet. 2007;370(9589):765-773.

6. Walker P, Mitchell P, Diamantea F, Warburton C, Davies L. Effect of primary-care spirometry on the diagnosis and management of COPD. Eur Respir J. 2006;28(5):945-952.

7. Vestbo J, Hurd SS, Agustí AG, et al. Global strategy for the diagnosis, management, and prevention of chronic obstructive pulmonary disease: GOLD executive summary. Am J Respir Crit Care Med. 2013;187(4): 347-365.

8. Overington JD, Huang YC, Abramson MJ, et al. Implementing clinical guidelines for chronic obstructive pulmonary disease: barriers and solutions. J Thorac Dis. 2014;6(11):1586-1596.

9. Scanlon PD, Connett JE, Waller LA, et al. Smoking cessation and lung function in mild-to-moderate chronic obstructive pulmonary disease: the Lung Health Study. Am J Respir Crit Care Med. 2000;161(2 pt 1):381-390.

10. Benzo R, Flume PA, Turner D, Tempest M. Effect of pulmonary rehabilitation on quality of life in patients with COPD: the use of SF-36 summary scores as outcomes measures. J Cardiopulm Rehabil Prev. 2000;20(4):231-234
11. Moullec G, Laurin C, Lavoie KL, Ninot G. Effects of pulmonary rehabilitation on quality of life in chronic obstructive pulmonary disease patients. Curr Opin Pulm Med. 2011;17(2):62-71.

12. Sabaté E. Adherence to Long-Term Therapies: Evidence for Action. Geneva: World Health Organization; 2003.

13. Ta M, George J. Management of COPD in Australia after the publication of national guidelines. Intern Med J. 2011;41:263-270.

14. Effective Practice and Organisation of Care (EPOC) [webpage on the Internet]. EPOC Resources for review authors. Norwegian Centre for the Health Services; 2015. Available from: http://epoc. cochrane.org/epoc-specific-resources-for-review-authors. Accessed June 3, 2016.

15. Abraham C, Michie S. A taxonomy of behavior change techniques used in interventions. Health Psychol. 2008;27(3):379-387.

16. Regan TW, Lambert SD, Girgis A, Kelly B, Kayser K, Turner J. Do couple-based interventions make a difference for couples affected by cancer? A systematic review. BMC Cancer. 2012;12(1):279.

17. Visser-Meily A, van Heugten C, Post M, Schepers V, Lindeman E. Intervention studies for caregivers of stroke survivors: a critical review. Patient Educ Couns. 2005;56(3):257-267.

18. Nakken N, Janssen DJ, van den Bogaart EH, et al. Informal caregivers of patients with COPD: Home Sweet Home? Eur Respir Rev. 2015; 24(137):498-504.

19. Bandura A. Social Learning Theory. New York: General Learning Corporation; 1971

20. Bainbridge HT, Cregan C, Kulik CT. The effect of multiple roles on caregiver stress outcomes. J Appl Psychol. 2006;91(2):490-497.

21. Simpson AC, Rocker GM. Advanced chronic obstructive pulmonary disease: impact on informal caregivers. J Palliat Care. 2008;24:49-54.

22. Kasikci M, Alberto J. Family support, perceived self-efficacy and selfcare behaviour of Turkish patients with chronic obstructive pulmonary disease. J Clin Nurs. 2007;16:1468-1478.

23. Trivedi R, Bryson C, Udris E, Au D. The influence of informal caregivers on adherence in COPD patients. Ann Behav Med. 2012;44: 66-72.

24. DiMatteo M. Social support and patient adherence to medical treatment: a meta-analysis. Health Psychol. 2004;23(2):207-218.

25. Martínez-Martín P, Forjaz MJ, Frades-Payo B, et al. Caregiver burden in Parkinson's disease. Mov Disord. 2007;22(7):924-931

26. Institute of Medicine. Crossing the Quality Chasm: A New Health System for the Twenty-First Century. Washington, DC: National Academy Press; 2001

27. Giacomini M, DeJean D, Simeonov D, Smith A. Experiences of living and dying with COPD: a systematic review and synthesis of the qualitative empirical literature. Ont Health Technol Assess Ser. 2012; 12(13): $1-47$

28. Pooler C. Qualitative evidence in chronic obstructive pulmonary disease. Handbook of Qualitative Health Research for Evidence-Based Practice [Internet]. Olson, Karin, Young, Richard A., Schultz, Izabela Z, editors. New York: Springer; 2016:291-318.

29. Moher D, Liberati A, Tetzlaff J, Altman DG; The PRISMA Group. Preferred reporting items for systematic reviews and meta-analyses: the PRISMA statement. PLoS Med. 2009;6(6):e1000097.

30. Boxall AM, Barclay L, Sayers A, Caplan GA. Managing chronic obstructive pulmonary disease in the community: a randomized controlled trial of home-based pulmonary rehabilitation for elderly housebound patients. J Cardiopulm Rehabil. 2005;25(6):378-385.

31. Egan E, Clavarino A, Burridge L, Teuwen M, White E. A randomized control trial of nursing-based case management for patients with chronic obstructive pulmonary disease. Lippincotts Case Manag. 2002;7(5):170-179.

32. Ojoo JC, Moon T, McGlone S, et al. Patients' and carers' preferences in two models of care for acute exacerbations of COPD: results of a randomised controlled trial. Thorax. 2002;57(2):167-169.

33. Abad-Corpa E, Royo-Morales T, Iniesta-Sánchez J, et al. Evaluation of the effectiveness of hospital discharge planning and follow-up in the primary care of patients with chronic obstructive pulmonary disease. J Clin Nurs. 2013;22(5-6):669-680. 
34. Aimonino Ricauda N, Tibaldi V, Leff B, et al. Substitutive "hospital at home" versus inpatient care for elderly patients with exacerbations of chronic obstructive pulmonary disease: a prospective randomized, controlled trial. J Am Geriatr Soc. 2008;56(3):493-500.

35. Monninkhof E, van der Valk P, van der Palen J, van Herwaarden C, Zielhuis G. Effects of a comprehensive self-management programme in patients with chronic obstructive pulmonary disease. Eur Respir J. 2003; 22(5):815-820.

36. Lainscak M, Kadivec S, Kosnik M, et al. Discharge coordinator intervention prevents hospitalizations in patients with COPD: a randomized controlled trial. J Am Med Dir Assoc. 2013;14(6):450.e1-e6.

37. Jonsdottir H, Amundadottir OR, Gudmundsson G, et al. Effectiveness of a partnership-based self-management programme for patients with mild and moderate chronic obstructive pulmonary disease: a pragmatic randomized controlled trial. J Adv Nursing. 2015;71(11):2634-2649.

38. Marques A, Jácome C, Cruz J, Gabriel R, Brooks D, Figueiredo D. Family-based psychosocial support and education as part of pulmonary rehabilitation in COPD: a randomized controlled trial. Chest. 2015; 147(3):662-672.

39. Ugalde A, Meinir K, Schofield P. Supporting informal caregivers of people with advanced cancer: a literature review. Aust J Cancer Nurs. 2011; 12(2):12-16.
40. Matthews AK, Sellergren SA, Manfredi C, Williams M. Factors influencing medical information seeking among African American cancer patients. J Health Commun. 2002;7(3):205-219.

41. DiMatteo MR. Social support and patient adherence to medical treatment: a meta-analysis. Health Psychol. 2004;23(2):207-218.

42. Xiaolian J, Chaiwan S, Panuthai S, Yijuan C, Lei Y, Jiping L. Family support and self-care behavior of Chinese chronic obstructive pulmonary disease patients. Nurs Health Sci. 2002;4(1-2):41-49.

43. Hoffman B, Stovall E. Survivorship perspectives and advocacy. Journal of Clinical Oncology. 2006;24:5154-5159.

44. Pedro LW. Quality of life for long-term survivors of cancer: influencing variables. Cancer Nurs. 2001;24(1): 1-11.

45. Bodenmann G, Cina A. Stress and Coping Among Stable-Satisfied, Stable-Distressed, and Separated/Divorced Swiss Couples: A 5-Year Prospective Longitudinal Study. Journal of Divorce \& Remarriage. 2005;44(1):71-89.

46. Manne $\mathrm{S}, \mathrm{Badr} \mathrm{H}$. Intimacy processes and psychological distress among couples coping with head and neck or lung cancers. Psychooncology. 2010;19(9):941-954.

\section{Publish your work in this journal}

The International Journal of COPD is an international, peer-reviewed journal of therapeutics and pharmacology focusing on concise rapid reporting of clinical studies and reviews in COPD. Special focus is given to the pathophysiological processes underlying the disease, intervention programs, patient focused education, and self management protocols.

\section{Dovepress}

This journal is indexed on PubMed Central, MedLine and CAS. The manuscript management system is completely online and includes a very quick and fair peer-review system, which is all easy to use. Visit $\mathrm{http}: / / \mathrm{www}$.dovepress.com/testimonials.php to read real quotes from published authors. 